\title{
Complications from Stents and Lack of Conversations
}

\author{
Romayne Gallagher* \\ Head, Division of Palliative Care, Department of Family and Community Medicine Providence Health Care, Canada \\ Clinical Professor, Division of Palliative Care, Department of Medicine, University of British Columbia, Vancouver, Canada
}

Received: September 09, 2015; Accepted: January 16, 2016; Published: April 19, 2016

*Corresponding author: Clinical Professor, Division of Palliative Care, Department of Medicine, University of British Columbia, Vancouver, Canada, Phone: 1-604-682-2344 ; Fax: 1-604-806-8556 ; Email: rgallagher@providencehealth.bc.ca

Keywords: ACAT-1; Kupffer cells; Inflammation; Nonalcoholic steatohepatitis

\section{Case Report}

A 59 year-old man had several months of epigastric distress and pain radiating to the back before presenting with obstructive jaundice. CT scan of the abdomen showed a $4 \mathrm{~cm}$ mass in the pancreas. The biliary obstruction was located $4 \mathrm{~cm}$ above the ampulla and resolved with the insertion of a Cotton Leung plastic stent. Lesions in the liver, seen on ultrasound, could not be confirmed as metastases on CT scan. Biopsy of the liver lesions by laparoscopy confirmed them as metastases so he was referred for chemotherapy.

One month later he developed increasing epigastric pain and vomiting. CT scan showed duodenal obstruction secondary to local tumor growth. An expanding metal stent was inserted via endoscopy and the vomiting stopped the next day. X-ray confirmed good position of the duodenal stent and since he was tolerating fluids he was discharged home the next day.

Fatigue, weakness and poor appetite persisted. He was given short-acting opioids as needed for ongoing epigastric pain. During this time his first appointment with the medical oncologist occurred but he was in too much pain to be considered for chemotherapy. He was advised to get his pain controlled and a referral for home nursing was completed.

Several days later he developed increasing right upper quadrant pain, weakness and confusion. On admission to hospital he was hypotensive, jaundiced and had severe right upper quadrant and epigastric pain. His lab values confirmed sepsis with a WBC of 11.2 giga/L with increased neutrophils. Liver function tests showed significant derangement with GGT $593 \mathrm{U} / \mathrm{L}$, ALP $602 \mathrm{U} / \mathrm{L}, \mathrm{LDH} 205 \mathrm{U} / \mathrm{L}$ and the total bilirubin was $38 \mathrm{umol} / \mathrm{L}$ (normal < 20) with a conjugated value of 30 umol/L (normal <6). His electrolytes and BUN showed slight derangement consistent with vomiting and the hemoglobin was $89 \mathrm{~g} / \mathrm{L}$. His eGFR and calcium were normal. A fentanyl infusion was started to control the pain and he was started on Pip/Tazo and Vancomycin for broad spectrum coverage of sepsis. A CT scan showed that both stents were in normal position and the stomach was decompressed. Significant biliary duct dilatation, not present on his last CT scan, was noted and there were two irregular fluid collections containing small bubbles of air - probable liver abscesses - that had also developed. The liver metastases had all grown in size in the interim. Clostridium perfringens and Streptococcus anginosus grew in his blood and were susceptible to the antibiotics.

The fentanyl infusion was titrated to effective pain relief but he remained delirious and died three days later.

The oncologist called the wife several days after he became aware he was in the hospital and was surprised to find he had died. He notes that the wife was angry and told him that both the patient and she felt let down by the medical system and the physicians and nurses who had seen them for his illness. The physician noted "unfortunately clinical deterioration in such as this is all too common in the context of metastatic pancreatic cancer".

This case is instructive for two reasons: the risk of serious sepsis in patients with stents and the bereavement reaction of the spouse.

Clostridium perfringens is an anaerobic normal inhabitant of the bowel and genital tract. Septicemia from this bacteria usually occurs in patients who are immunocompromized (malignancy, diabetes etc) and have had a recent abdominal or pelvic procedure [1]. The mortality rate is extremely high. Streptococcus anginosus is also associated with abscesses in those who are immunocompromized.

Therapy for the complications of pancreatic cancer has evolved tremendously over the last 20 years with the introduction of stenting by endoscopy. Complications such as the liver abscesses, are being reduced by the use of covered self expandable metal stents that have a lower risk of cholangitis and infection [2]. Stenting shows a shortened time to resumption of fluids and food, reduced hospital stay and costs when compared with surgery [3].

A recent review [4] of pancreatic cancer noted that on diagnosis $90 \%$ of tumors are already locally or systemically involved and therefore not operable. The average survival for those who are not operable is 4 months with the range of 3-11 
months. Those with metastatic disease account for the lower survival range [5] . Of the $10 \%$ who qualify for resection, two thirds develop a recurrence by two years and the five year survival ranges from 3 to $25 \%$. While treatment of the symptoms and complications of the tumor have evolved dramatically [5], the overall survival not improved significantly because of late presentation.

Despite having multiple costly interventions to successfully diagnose and manage the symptoms of his cancer the spouse was angry at the healthcare professionals involved in his care. According to the spouse, the surgeon, oncologist and family physician did not provide any indication of the prognosis. The patient and spouse did discuss the rapidly progressive worsening of his condition and did wonder whether he would survive. An expression of fear about this occurred between the two of them but the final infectious episode intervened. The final illness came on unexpectedly and precipitously. The patient became delirious and was unable to communicate meaningfully prior to his death.

While there are barriers to discussing prognosis and having end-of-life conversations, physician barriers are more common than any patient or system factors [6]. Having a conversation about prognosis and concerns of the patient results in less use of ineffective therapies, more use of palliative care and reduced family distress [7]. Studies have shown that most patients want truthful information and that it is not harmful to them or their family [8]. In this case, the lack of prognostic information led to a feeling of dissatisfaction with the care, despite multiple therapeutic interventions, and a more complicated grief reaction. These conversations cannot be left until the provider thinks that all treatment options have been exhausted as this patient developed an uncommon complication of the stent and did not survive long enough to receive systemic therapy for the tumor. A good article about how to discuss prognosis is available [9].

Having the awareness of a shortened life allows opportunity for reconciliation, preparation and expressions of love. The healing of the survivors is nourished by these memories. Communication about prognosis is an intervention - as essential as any diagnostic or surgical procedure.

\section{References}

1. van Bunderen CC, Bomers MK, Wesdorp E, Peerbooms P, Veenstra J. Clostridium perfringens septicaemia with massive intravascular haemolysis: a case report and review of the literature. Neth J Med. 2010;68(9):343-346.

2. Dumonceau JM, Tringali A, Blero D, Devière J, Laugiers R, Heresbach $D$, et al. Biliary stenting: indications, choice of stents and results: European Society of Gastrointestinal Endoscopy (ESGE) clinical guideline. Endoscopy. 2012;44(3):277-298. doi: 10.1055/s-00311291633.

3. Chandrasegaram MD, Eslick GD, Mansfield CO, Liem H, Richardson $\mathrm{M}$, Ahmed $\mathrm{S}$, et al. Endoscopic stenting versus operative gastrojejunostomy for malignant gastric outlet obstruction. Surg Endosc. 2011;26(2):323-329. doi: 10.1007/s00464-011-1870-3.

4. Majumder S, Chubineh S, Birk J. Pancreatic cancer: an endoscopic perspective. Expert Rev Gastroenterol Hepatol. 2012;6(1):95-103. doi: 10.1586/egh.11.93.

5. Alexander Stark and O. Joe Hines. Endoscopic and and Operative Palliation Strategies for Pancreatic Ductal Adenocarcinoma. Seminars in Oncology. 2015;42(1):163-176. doi: 10.1053/j. seminoncol.2014.12.014.

6. Keating NL, Landrum MB, Rogers SO Jr., Baum SK, Virnig BA, Huskamp HK et al. Cancer 2010; 116(4): 998-1006

7. Wright AA, Zhang B, Ray A, Mack JW, Trice E, Balboni T, et al. Associations between end-of-life discussions, patient mental health, medical care near death, and caregiver bereavement adjustment. JAMA. 2008;300(14):1665-1673. doi: 10.1001/jama.300.14.1665.

8. Innes S, Payne S. Advanced cancer patients' prognostic information preferences: A review. Palliat Med. 2009;23(1):29-39. doi: 10.1177/0269216308098799.

9. Campbell TC, Carey EC, Jackson VA, Saraiya B, Yang HB, Back AL, Arnold RM. Discussing Prognosis: Balancing Hope and Realism. Cancer J. 2010;16(5):461-466. doi: 10.1097/PP0.0b013e3181f30e07. 